\title{
Anagram solving: Does effort have an effect?
}

\author{
MARY ANN FOLEY \\ Skidmore College, Saratoga Springs, New York \\ HUGH J. FOLEY \\ Union College, Schenectady, New York \\ and \\ ALICE WILDER and LESLIE RUSCH \\ Skidmore College, Saratoga Springs, New York
}

\begin{abstract}
The purpose of these studies was to explore the role of effort in remembering anagrams and their solutions. In Experiment 1, we compared the effects on memory of copying words, typing them as solutions for easy anagrams, or typing them as solutions for difficult anagrams. Solving anagrams involved more effort than did simply typing words, as indexed by response time. However, this effort facilitated recall for solutions to easy anagrams but not for solutions to difficult anagrams. In Experiment 2, we compared memory for anagrams and their solutions using a frequency-judgment task. Memory for solutions was better than memory for anagrams, and this difference was not affected by anagram difficulty. The results of these studies have implications for our understanding of the role of effort in remembering.
\end{abstract}

Zacks, Hasher, Sanft, and Rose (1983) reported that the effort involved in generating solutions for anagrams did not facilitate memory for those solutions. In some of their studies, subjects solved easy and difficult anagrams varying numbers of times and then recalled solutions for those anagrams. Presumably, the processes involved in working through problems to their solutions enhance memory (e.g., Jacoby, 1978). If solving difficult anagrams requires more effortful processing, it seems reasonable to expect, as Zacks et al. did, that memory for solutions to difficult anagrams would be better than memory for solutions to easy anagrams. However, this was not the case. Recall of solutions to difficult anagrams was equivalent to recall of solutions to easy anagrams.

In the present experiments, we considered two possible reasons for the negative findings reported by Zacks et al. (1983). First, there were no baseline conditions in their studies. It may be that the effort involved in anagram solving enhances memory, relative to less effortful tasks, but nears an asymptote, so that there is no additional advantage following the solution of difficult anagrams. This possibility was tested in Experiment 1 by comparing anagram solving with a less effortful task. Another reason for the negative findings of Zacks et al. may be related to the way the effects of effort were assessed. When solving ana-

Portions of this research were presented at the Eastern Psychological Association Meetings in April 1988 and April 1989. This research was supported by grants from NSF (BNS 84-18791) and the Spencer Foundation. We gratefully acknowledge Frank Durso for his insightful comments on earlier versions of the manuscript. Request for reprints should be addressed to Mary Ann Foley, Department of Psychology, Skidmore College, Saratoga Springs, NY 12866, or Bitnet (Foley@Skidmore). grams, subjects may focus on the anagrams themselves rather than on their solutions, and the effort involved in generating solutions may be associated with the anagrams rather than with their solutions. This idea was tested in Experiment 2 by comparing memory for anagrams and their solutions in a frequency-judgment task.

\section{EXPERIMENT 1}

\section{Method}

Subjects. Thirty-six undergraduates at Skidmore College were paid $\$ 3$ to participate.

Materials. Twenty words, 5-6 letters in length, were drawn from the Paivio, Yuille, and Madigan (1968) norms so that all were highly concrete $(M=6.10)$, imageable $(M=6.41)$, and meaningful ( $M$ $=6.64$ ). An easy and a difficult anagram were constructed for each word following guidelines established by others (Mayzner \& Tresselt, 1958; Zacks et al., 1983). An easy anagram was defined as one in which the letter order was maximally similar to the word, whereas a difficult anagram was one in which the letter order was maximally dissimilar to the ordering of the letters in the word.

Procedure. All subjects were run individually under incidental conditions. They were told the purpose of the study was to norm material for their complexity. Depending upon condition, the subjects were told that task complexity was measured as a function of the time it took to type words (copying them or generating them as solutions to anagrams). The subjects were assigned to one of three conditions: (1) typing individual words presented on a monitor, (2) solving easy anagrams by typing their solutions, or (3) solving difficult anagrams by typing their solutions.

In the anagram conditions, first-letter prompts were provided and the subjects were told that each anagram had only one solution. Response time was measured once the subject initiated typing of the response. If a subject entered an incorrect letter, he/she was prompted to begin again, and timing was resumed. Subjects were given unlimited time to type the words, but they were encouraged to be as quick and accurate as possible. Following the first phase, 
Table 1

Mean Solution Times (in sec) and Recall in Experiment 1

\begin{tabular}{lcc}
\hline \multicolumn{1}{c}{ Condition } & Solution Time & Recall \\
\hline Difficult Anagrams & 10.50 & 4.75 \\
Easy Anagrams & 5.24 & 6.16 \\
Type Words & 1.23 & 3.91 \\
\hline
\end{tabular}

Note-Maximum recall per cell $=20$.

the subjects were surprised with one free-recall trial. Stimulus presentations and response times were controlled by an Apple Ile computer.

\section{Results}

Response times. Solution time is a measure of anagram difficulty (Mayzner \& Tresselt, 1958; Zacks et al., 1983). An analysis of variance (ANOVA) showed that mean response times varied with condition $[F(2,33)=52.13$, $p<.001 ;$ see Table 1]. Post hoc analyses using Tukey's critical mean difference test showed that the time it took to solve difficult anagrams was greater than the time it took to solve easy ones. The time to solve anagrams (easy or difficult) was greater than the time to simply type words.

Mean recall. An ANOVA showed that recall varied with condition $[F(2,33)=4.80, p<.01$; see Table 1$]$. Tukey's critical difference test showed that recall was higher for subjects who solved easy anagrams than for those who solved difficult ones or for those who simply typed words. Although recall for words typed as solutions to difficult anagrams tended to be higher than that for words simply typed, this difference was not statistically significant. Thus, whereas the effort involved in solving difficult anagrams did not enhance memory for their solutions, the effort involved in solving easy ones did.

\section{EXPERIMENT 2}

In Experiment 2, we compared memory for anagrams and their solutions using a frequency-judgment task. This type of task was selected because the use of recall would put subjects remembering anagram solutions at an unfair advantage, relative to subjects trying to recall the original anagrams. In addition, frequency judgments are sensitive to differences in material types (Foley, Foley, \& Zanfardino, 1989; Rao, 1983).

\section{Method}

Subjects. Forty undergraduates from Skidmore College were paid $\$ 3.00$ to participate.

Materials. Thirty-six words, all high in frequency in the English language (AA or A from Thorndike-Lorge, 1944, norms), were selected from Olson and Schwartz's (1967) norms for single anagram solutions for five-letter words. An easy and a difficult anagram were constructed for each word following the procedure described in Experiment 1.

Twelve of the words were randomly selected as distractors for subsequent recognition tests, and 24 were designated as targets. For any 1 subject, half the anagrams were easy to solve and the other half were difficult. Of the 12 easy and 12 difficult anagrams, one third were presented once, another third twice, and another third four times. Thus, there was a total of 56 trials, occurring in random order, during the solution-generation phase. Several lists were constructed to counterbalance anagram difficulty and frequency.

Procedure. The subjects were told we needed to classify anagrams as easy or difficult, and that one index of difficulty is the time it takes to solve anagrams. They were also told that each anagram had only one solution, and that some anagrams might appear more than once. After a warning signal appeared in the center of a monitor, an anagram was presented and remained in view until the subject solved the anagram. Response time was measured once a typing response was initiated. A booklet of scrap paper was available if the subjects wanted to try to solve the anagrams by writing possible solutions. Only 1 subject did so, and for only four of the trials. When the subject solved the anagram, he/she was instructed to press a key and then enter his/her solution. Of the 40 subjects, 8 made mistakes; however, these 8 produced the correct solutions $99 \%$ of the time (out of 56 trials). Stimulus presentations and time to solve the anagrams were controlled and recorded by an Apple Ile computer.

After solving anagrams, the subjects were surprised with one of two types of memory tests. Subjects in the solution condition were presented with a list of words, 24 of which were solutions they had generated and 12 of which were distractors. Subjects in the anagram condition were presented with the 24 original anagrams, 6 distractors which were rearrangements of old anagrams, and 6 distractors which were new anagrams. In both conditions, the subjects indicated whether the items were "old" or "new"; if they reported "old," they then judged the frequency with which they had generated solutions or had seen the anagrams, respectively.

\section{Results}

Solution times. The overall time it took to solve easy anagrams $(M=4.96 \mathrm{sec})$ was less than that for difficult anagrams $(M=13.17 \mathrm{sec})[F(1,57)=57.76, p<.001]$.

As mentioned, some anagrams were solved on one, two, or four trials. Table 2 summarizes the mean response times corresponding to presentation frequency. A 3 (presentation frequency) $\times 2$ (type of anagram) $\times 2$ (test condition) ANOVA on the anagrams presented four times indicated that mean solution times decreased with attempts to solve the anagrams $[F(3,117)=69.66, p<.001]$, and this decrease was greater for difficult anagrams $[F(3,117)$ $=28.37, p<.001]$. The time it took to solve easy anagrams was significantly less than the time it took to solve

Table 2

Mean Solution Times (in sec) Separated by Presentation Frequency and Anagram Difficulty in Experiment 2

\begin{tabular}{ccc}
\hline $\begin{array}{c}\text { Presentation } \\
\text { Trial }\end{array}$ & \multicolumn{2}{c}{ Anagram Difficulty } \\
\cline { 2 - 2 } 1 & Anagram presented four times & Difficult \\
\hline & 8.20 & 27.55 \\
3 & 3.02 & 10.03 \\
4 & 1.71 & 4.97 \\
& 1.18 & 2.74 \\
1 & Anagram presented two times \\
2 & 8.88 & 21.19 \\
& 2.11 & 10.52 \\
1 & Anagram presented one time \\
\end{tabular}


Table 3

Mean Frequency Judgments and Mean Hits in Experiment 2

\begin{tabular}{|c|c|c|c|c|c|c|}
\hline \multirow{3}{*}{$\begin{array}{l}\text { Presentation } \\
\text { Frequency }\end{array}$} & \multicolumn{4}{|c|}{ Mean Frequency Judgments } & \multirow{2}{*}{\multicolumn{2}{|c|}{ Mean Hits }} \\
\hline & \multirow{2}{*}{$\begin{array}{c}\text { Easy } \\
\text { Anagrams }\end{array}$} & \multirow{2}{*}{$\begin{array}{c}\text { Difficult } \\
\text { Anagrams }\end{array}$} & \multirow{2}{*}{$\begin{array}{c}\text { Easy } \\
\text { Solutions }\end{array}$} & \multirow{2}{*}{$\begin{array}{l}\text { Difficult } \\
\text { Solutions }\end{array}$} & & \\
\hline & & & & & Easy & Difficult \\
\hline 1 & 1.00 & .98 & 1.22 & 1.02 & 3.12 & 2.87 \\
\hline 2 & 2.26 & 1.99 & 2.45 & 2.40 & 3.65 & 3.17 \\
\hline 4 & 3.30 & 3.43 & 3.55 & 3.66 & 3.65 & 3.52 \\
\hline
\end{tabular}

Note-Maximum hits per cell $=4$.

difficult ones $[F(1,39)=37.45, p<.001]$, but there was no difference between test conditions. Similar patterns were observed for anagrams presented one or two times; easy anagrams were solved more quickly in each case. For anagrams presented twice, there was also a significant interaction between presentation frequency and anagram type.

Frequency judgments. An ANOVA including presentation frequency, type of anagram, and type of test as factors showed that mean frequency judgments differed with increases in presentation frequency $[F(2,76)=125.97$, $p<.001]$. Estimates were higher for solutions than for anagrams $[F(1,38)=4.33, p<.05$; see Table 3]. As the next analysis shows, frequency judgments were more accurate for words than for anagrams.

Absolute error estimates of the frequency judgments were calculated as the unsigned difference between each frequency estimate and the actual frequency level, and averaging across subjects. Although error rates were generally low, mean errors increased with increases in presentation frequency $[F(2,76)=16.23, p<.01]$. The means were $.02, .23$, and .64 for items presented one, two, and four times, respectively. Errors were less on solutions than on anagrams $[F(1,38)=4.08, p<.05]$.

Mean hits. Frequency judgments were also scored for simple recognition (i.e., old items receiving a frequency estimate of 1 or more). An ANOVA showed that hits were higher for more frequent items $[F(2,76)=12.98$, $p<.001]$, higher for easy items than for difficult ones $[F(1,38)=7.03, p<.01]$, and comparable in the two testing conditions. The means are shown in Table 3, collapsed across testing conditions.

False positives. There were fewer false positives in the solution condition $(M=.06)$ than in the anagram condition $(M=.88)[F(1,34)=26.87, p<.01]$. When false positives on the anagram test were separated for new anagrams and new arrangements of old anagrams, errors were significantly higher for new arrangements $[F(1,18)$ $=32.56, p<.001]$. The means were .04 and .82 , respectively.

\section{DISCUSSION}

The results of these experiments are important for several reasons. Both experiments replicate the results of Zacks et al. (1983) in demonstrating that the effort involved in solving difficult anagrams exceeds that involved in solving easy anagrams. Furthermore, recall of solutions to difficult anagrams did not exceed that for easy ones (Experiment 1). In addition, memory for difficult anagrams was not better than memory for easy ones (Experiment 2).

However, our findings show that effort enhances recall for anagram solutions under some conditions when appropriate controls are included. Words typed as solutions to easy anagrams were recalled better than words simply typed (Experiment 1).

The reason why the effort involved in solving difficult anagrams does not enhance memory is still not clear. However, it is not the only case in which effort fails to enhance remembering (e.g., Einstein, McDaniel, Bowers, \& Stevens, 1984). Difficult anagram solving may be an extreme version of item-specific encoding. As subjects attempt to solve difficult anagrams, their focus is on letter rearrangements, and the words as semantic units are only available upon solution. Thus, relational processing (e.g., implicit associative responses, spontaneous covert elaborations, inferences) typically actived in semantic tasks may not be elicited (e.g., McDaniel, Einstein, \& Lollis, 1988). On the other hand, when easy anagrams are solved, relational processing may be more likely to occur automatically because less time is spent solving anagrams. A fruitful direction for subsequent research would involve the comparison of anagram solving and other kinds of generative tasks in situations prompting relational and item-specific encoding. This direction of research should help to clarify why it is that effort sometimes fails to enhance remembering.

\section{REFERENCES}

Einstein, G. O., McDaniel, M. A., Bowers, C. A., Stevens, D. T. (1984). Memory for prose: The influence of relational and propositionspecific processing. Joumal of Experimental Psychology: Learning, Memory, \& Cognition, 10, 133-143.

Foley, H. J., Foley, M. A., Zanfardino, D. (1989). Do we process frequency information automatically? Unpublished manuscript.

JACOBY, L. (1978). On interpreting the effects of repetition: Solving a problem versus remembering a solution. Journal of Verbal Leaming \& Verbal Behavior, 17, 649-667.

MAYZner, M. D., \& Tresselt, M. E. (1958). Anagram solution times: A function of letter order and word frequency. Journal of Experimental Psychology, 56, 376-379.

MCDaniel, M. A., Einstein, G. O., \& Lolus, T. (1988). Qualitative and quantitative considerations in encoding difficulty effects. Memory \& Cognition, 16, 8-14.

OLSON, R., Schwartz, R. (1967). Single and multiple solution five- 
letter words. Psychonomic Monograph Supplements, 2(8, Whole No. 24). 105-152.

Paivio, A., Yullle, J., \& Madigan, S. (1968). Concreteness, imagery and meaningfulness values for 925 nouns. Journal of Experimental Psychology Monographs, 76(1, Pt. 2).

RAo, K. V., (1983). The word frequency effect in situational frequency estimation. Joumal of Experimental Psychology: Leaming, Memory, \& Cognition, 9, 73-91.
THORNDIKE, E. L., \& LORGE, I. (1944). The teacher's word book of 30,000 words. New York: Teacher's College Press.

Zacks, R., Hasher, L., SAnft, H., \& Rose, K. C. (1983). Encoding effort and recall: A cautionary note. Journal of Experimental Psychology: Learning, Memory, \& Cognition, 9, 747-756.

(Manuscript received August 28, 1987; revision accepted for publication January 27,1989 .) 